\title{
Geopolítica e o domínio aeroespacial: da supremacia da aviação militar à exploração espacial por fusão nuclear
}

\author{
Geopolitics and the aerospace domain: \\ from military aviation supremacy \\ to the nuclear fusion space exploration
}

\section{FERNANDA DAS GRAÇAS CORRÊA ALCIDES EDUARDO DOS REIS PERON LUIZ FABRICIO THAUMATURGO VERGUEIRO}

\section{INTRODUÇÃO}

Se você entende como o universo funciona, de certa forma pode controlá-lo.

Stephen Hawking (1942-2018)

Para alguns autores, a Geopolítica surgiu da junção da Geografia Política com a própria Ciência Política. Assim compreendendo, fica-nos mais claro que a Geopolítica se apóia na lógica do poder do Estado, mas com uma ótica da Política. Neste breve histórico, passaremos pelas teorias dos domínios marítimos, terrestres e aéreo para nos dirigirmos à visão futura: o domínio do espaço sideral. Por outro lado, a experiência das últimas décadas parece apontar para outras visões de domínio no futuro.

Se balizarmos no tempo, podemos considerar o geógrafo alemão Friedrich Ratzel (1844-1904) como o estudioso que deu início aos estudos geopolíticos, em 1880. Baseou-se nos grandes espaços dos EUA, cujas conquistas se basearam na marcha para o Oeste, uma concretização da

Fernanda das Graças Corrêa - Pós-doutoranda em Ciências Militares e professora visitante da Escola de Comando e Estado Maior do Exército (ECEME).

Alcides Eduardo dos Reis Peron - Doutor em Política Científica e Tecnológica pela Universidade Estadual de Campinas (UNICAMP).

Luiz Fabricio Thaumaturgo Vergueiro - Doutor em Direito Internacional pela Faculdade de Direito da Universidade de São Paulo. 
doutrina do Destino Manifesto. Havia, então, um determinismo geográfico, onde espaço e posição territoriais definiam o espaço vital dos Estados, que justificava uma tendência à expansão por absorção e pelo entendimento da fronteira como um órgão periférico do Estado.

Dez anos depois, o almirante Alfred Thayer Mahan (1840-1914) propôs que o "controle do mar seria a chave para o domínio do mundo". O contexto internacional lhe era favorável: vivia-se o declínio do poder inglês e a expansão da frota mercante, impulsionada pelo navio a vapor e a abertura do canal de Suez. De acordo com Mahan, "para adquirir esse poder, é necessário possuir um forte comércio exterior, portanto, uma frota mercante e colônias, além de uma frota de guerra e bases navais para proteger as linhas de comunicação" (Araújo Neto 2011, 91). Os EUA tinham, então, suas fronteiras terrestres seguras, a população concentrada no litoral, costas extensas e bons portos em ambos os oceanos. Foi fácil, portanto, colocar a teoria do domínio dos mares, apoiada no poder naval e no uso do mar. A consequência foi o início de um período de hegemonia dos EUA.

Em 1904, o geógrafo inglês Halford John Mackinder (1861-1947) apostou na supremacia do poder terrestre. Vivia-se o crescimento das ferrovias e das novas locomotivas e Mackinder, ao observar este fenômeno na Europa criou o conceito Heartland - o coração continental que projetaria este poder. Como a história da Europa se subordinava à Ásia, a Eurásia bem servia para ser a Ilha Mundial. Conclusivamente, quem dominasse a Europa Oriental controlaria esta Ilha e, assim, dominaria o mundo.

A Primeira Guerra Mundial serviu de palco para um confronto entre os poderes marítimo e terrestre, devido à Alemanha, neste momento, ter aberto duas frentes, cada uma delas com tendência a diferentes teorias de poder: a França, alinhada à estratégia mahaniana, por possuir costa em dois teatros marítimos; e a Rússia, como heartland da guerra.

Surgiram, então, duas correntes: a do professor estadunidense Nicholas J. Spykman (1893-1943), favorável à consolidação do poder marítimo, com os EUA cercando o heartland valendo-se das Rimlands - regiões anfíbias periféricas da Eurásia, aliadas dos EUA; e do general Karl Ernst Haushofer (1869-1946), que defendia que a Alemanha deveria oferecer tecnologias e recursos econômicos ao Oriente, em troca do espaço vital que necessitava. Os resultados podem ser sintetizados no início da Guerra Fria; isolamento do bloco soviético; na criação da Organização do Tratado do Atlântico Norte (Otan) e do Pacto de Varsóvia e o surgimento da teoria defendida da supremacia do poder aéreo pelo general Giulio Douhet (1869-1930). 


\section{O DOMÍNIO DO PODER AÉREO}

Este general italiano concebeu uma nova arma, surgida no contexto da Primeira Guerra Mundial - o avião - que permitiria aos Estados conquistar o domínio do ar. defendia "que o avião poderia fazer sentir a sua acção para além do alcance das armas de superfície e em qualquer ponto, maximizando o ponto de aplicação da força, causando grau de incerteza, diminuindo a liberdade de acção do antagonista" (Moreira e Cardoso 1994, 38). Isto significa que, para Douhet, domínio do poder aéreo era destruir o poder aéreo do inimigo. Conforme aponta Pedro Miguel Xavier Estrada Fontes Pinto,

Giulio Douhet apresenta quatro pontos essenciais para a compreensão da guerra futura, que são o articulado conclusivo de todo o seu pensamento sobre o poder aéreo: assumirá caráter total; a urgência da aquisição do domínio aéreo para se garantir a vitória; a violência será tremenda assim como a rapidez de decisão; será um conflito no qual a vitória caberá àquele que melhor se tiver preparado doutrinalmente e em meios (Pinto 2003, 163).

O resultado que Douhet alcançou nas perspectivas futuras do poder aéreo foi que, era necessária uma aviação independente do poder terrestre e do poder naval, que estivesse sempre em prontidão para atuar nos diversos teatros de operações, e fortemente armada.

Outro teórico que foi fundamental na criação de uma aviação militar independente foi o estadunidense William Mitchell (1944-2010). Mitchell afirmava que,

o advento do poder aéreo, que pode ir direto aos centros vitais e neutralizá-los ou destruí-los, deu uma configuração inteiramente nova ao velho sistema de se fazer uma guerra. Compreende-se agora que o principal exército inimigo em campo é um falso objetivo, e que os objetivos reais são os centros vitais. [...] O resultado da guerra aérea será forçar decisões rápidas. O poder aéreo superior provocará tal devastação no país oponente, que uma campanha extensa será impossível (Almeida 2006, 19).

Douhet e Mitchell tinham apenas duas diferenças pontuais: enquanto Douhet se posicionava mais como um acadêmico, Mitchell não sabia lidar com as críticas de políticos quanto ao emprego da aviação militar. No entanto, enquanto Mitchell era profundo conhecedor de aviões militares e do emprego de modelos diferentes de aviões militares, enfatizando o combate aéreo, Douhet não estava familiarizado com aspectos técnicos e operacionais da aviação militar e defendia o emprego de um único mo- 
delo de avião militar: os bombardeiros. ${ }^{1}$ Para o teórico italiano, a força aérea deveria ser independente da Marinha e do Exército, na medida que ela era a responsável pelas aeronaves que realizariam o combate aéreo em condições extremas. Caberia, assim, às forças aéreas auxiliares da Marinha e do Exército apoiarem as operações em que os bombardeiros seriam empregados. Ambos os teóricos defendiam a aniquilação total dos inimigos por meio do combate aéreo destruindo as capacidades logísticas ${ }^{2}$ e fabris e obrigando o inimigo a desistir de lutar na guerra. Embora no início do século XX a Itália e a Bulgária já tivessem empregado aviões militares em conflitos, foi na Primeira Guerra Mundial que os aviões militares passaram a ser usados em missões de defesa, ataque e reconhecimento. Em 1947, um avião experimental pilotado por Chuck Yeager (1923-) tornou possível a propulsão por reação romper a barreira natural da velocidade de 1.235 $\mathrm{km} / \mathrm{h}$. Esta façanha tornou a barreira da velocidade do som o grande marco para a medição de velocidade. (Panazzolo Neto 2013, 47)

Outro teórico da supremacia do poder aéreo foi oficial aviador John Richard Boyd (1927-1997) da Força Aérea dos EUA, o qual revolucionou o combate aéreo no curso da Segunda Guerra Mundial. Pilotando o caça F-86 Sabre, Boyd depreendeu que a capacidade de observação aprimorada, aliada à maior agilidade da aeronave, apresentava grandes chances de sucesso no combate aéreo.

Os MIG eram, em muitos aspectos, tecnologicamente superiores aos aviões americanos, mas tinham um ponto fraco: a resposta do avião aos controles de vôo era mais lenta que a dos aviões americanos. Essa limitação do MIG acabaria sendo o seu "calcanhar de Aquiles". O poderoso sistema hidráulico que moveu os controles de vôo Sabre deu aos pilotos americanos uma vantagem decisiva sobre seus oponentes no combate corpo-a-corpo: a capacidade de passar de uma manobra a outra muito mais rapidamente. Desta forma, no momento em que o MIG começou a reagir a uma manobra inicial do Sabre, este, graças a uma rápida contramanobra, quebrou a inércia inicial e tornou o movimento do Mig inadequado para a nova situação criada pelo americano (Marí, 32).

Durante a Guerra, Boyd desenvolveu o conceito de manobra batizado de flat-plating-the-bird, segundo o qual, no combate aéreo, ele reduzia a velocidade da sua aeronave diante da aeronave inimiga, permitindo que esta a ultrapassasse (overshoot) e manobrava finalizando com rajadas certeiras no alvo inimigo. A maior capacidade de manobra e a maior energia das aeronaves permitiam que elas explorassem novas posições no combate aéreo. Ao repassar esses conhecimentos para os pilotos, a superioridade tática 
dos caças estadunidenses frente aos caças russos MIG-15 resultou em 792 MIGs abatidos.

De acordo com Boyd, a incerteza, a complexidade e a desordem caracterizam o meio ambiente produzindo o caos. Assim, este estrategista criou o ciclo de tomada de decisão conhecido por Observação, Orientação, Decisão e Ação (OODA) como estratégia de superação do caos. Segundo Telmo Roberto Machry,

usando essa construção, advoga que obterá sucesso aquele que conseguir completar o ciclo com vantagem de tempo sobre o oponente, de forma que os atrasos de cada ciclo somados começam a prejudicar o tempo de reação do inimigo, conduzindo o sistema de comando e controle do adversário rumo ao colapso. A sobrecarga no sistema operacional provoca a desorientação mental do sistema de comando e controle do oponente, afetando a vontade moral e, consequentemente, a operacionalidade dos meios físicos (Machry 2006, 51).

Quando foi para a reserva, Boyd se tornou consultor da Força Aérea dos EUA e do Pentágono. Os conceitos desenvolvidos por Boyd ampliaram os conhecimentos teóricos e doutrinários sobre domínio do ar, à medida que desenvolveram uma estrutura mental que viabilizou as tomadas de decisões táticas e operacionais e possibilitou a conquista do objetivo estratégico, influenciando decisivamente no desenvolvimento das novas gerações de caças e nos manuais militares das forças aéreas dos EUA e de países ocidentais. Nos EUA, a revolução tecnológica se dava pela nova geração de caças supersônicos que explorassem novas posições no combate aéreo, considerando energia e manobrabilidade como fatores determinantes na superioridade aérea.

O coronel da Força Aérea dos EUA, John Ashley Warden III (1947-), também trouxe interessantes concepções teóricas para o debate da supremacia do poder aéreo, a partir da argumentação histórica e de suas observações dos ataques aéreos ao Iraque da Operação Tempestade do Deserto (1990-1991). Esta Operação foi resultado de uma coalizão de 31 países contra a invasão do Iraque no Kuwait, em agosto de 1990. Com a economia em déficit, Saddam Hussein, após o Kuwait ter se negado a diminuir a produção de petróleo para que a produção de petróleo do Iraque fosse reequilibrada no mercado internacional, decidiu invadir e transformar este emirado em província iraquiana. O potencial petrolífero da região era estratégico para o mercado internacional e diversos países e o Conselho de Segurança das Nações Unidas decidiram promover embargos econômicos ao Iraque e intervir militarmente. Assim que foi ordenada a Operação, em janeiro de 1991, por 14 horas os aviões da coalizão realizaram mais de 1.300 missões, bombardeando bases militares e complexos industriais do Iraque. 
Warden, em seu livro The Air Campaign. Planning for Combat, enfatiza bastante que as operações nos teatros de guerra devem estar alicerçadas em planejamento, e percebesse-se nitidamente a influência do general chinês Sun Tzu (545 A.C. - 470 A.C.) em suas análises. Nestes planejamentos, devem ser considerados os centros de gravidade de ar, a fase das operações e os recursos necessários. De acordo com Warden,

a natureza do inimigo é muito importante, especialmente se o plano de campanha aérea visse outra coisa senão o desgaste direto. Existem mais maneiras de categorizar um inimigo do que pode ser razoavelmente integrado e usado. Por exemplo, ele pode ser racional, irracional, fanático, rígido, flexível, independente, inovador, determinado ou doutrinário. Na medida em que um inimigo pode ser designado para qualquer uma dessas categorias, seus planos podem ser antecipados, e a forma como ele reagirá a uma nova situação pode ser prevista. A história fornecerá alguma ajuda na avaliação do inimigo, embora seja tolice supor que as projeções lineares do comportamento passado serão absolutamente válidas. O outro lado de conhecer o inimigo é conhecer a si mesmo (Warden 1988).

Em sua ótica, nenhum Estado pode desfrutar de superioridade aérea sem conhecer seu inimigo e sem avaliar os riscos nas operações, daí a importância de avaliar de onde se está em relação ao inimigo e ser cauteloso na campanha aérea. Há casos, em que as bases inimigas não podem ser atacadas e só se pode se defender de contra-ataques inimigos. Há outros casos em que o planejamento deve orientar como encontrar o inimigo sobre as linhas e ainda outros em que não há combate aéreo e o planejamento deve apenas definir ações de contingência. Citando as palavras do general confederado Thomas Jonathan Stonewall Jackson (1824-1863), Warden as endossa, afirmando que o dever de um comandante é mistificar, enganar e surpreender e esta injunção se aplica tanto ao espaço aéreo quanto ao chão. Enganar o inimigo pode ser uma arma poderosa à medida que nada poderia ser melhor numa guerra do que direcionar o inimigo para teatro de operações errado ou lançar bombas em parte de um deserto estéril. A influência clausewitziana é também perceptível em suas análises quando afirma que, na guerra, é preciso modificar a vontade do inimigo. Segundo Warden, a dissimulação poderia levar o inimigo a pensar que um ataque consistiria em apenas dez aeronaves, quando na verdade seria de vinte. $\mathrm{O}$ desapontamento num ataque inimigo é tão bem-sucedido que é uma estratégia que, nos planejamentos futuros, pode ser empregada e poderá ser bem-sucedida de novo. 


\section{O DOMÍNIO DO ESPAÇO SIDERAL}

Após o fim da Segunda Guerra Mundial, iniciou-se uma corrida tecnológica para o domínio do espaço sideral, o que promoveu diversos avanços tecnológicos que vão desde o desenvolvimento de novos materiais e aprimoramento de motores até o de armamentos e satélites meteorológicos e de comunicação. Enquanto a vitória dos EUA se tornou visível pelos avanços tecnológicos em armamentos e na economia, a vitória da então União Soviética estava concentrava nas capacidades e competências militares do Exército Vermelho. Este país, embora vitorioso, saiu da guerra fragilizado economicamente. A Guerra Fria, já prevista pelos atores evolvidos no contexto da Segunda Guerra Mundial, se constituiu partilhando o mundo em áreas estratégicas de influência e interferência, em que estadunidenses e soviéticos se rivalizavam sem emprego de força, por meio de uma corrida armamentista que disputava o poder no espaço, inclusive com testes e lançamentos de bombas nucleares.

Os EUA foram os primeiros e até hoje os únicos a lançar bombas atômicas contra alvos civis e o monopólio deste armamento foi exclusivo dos EUA de 1945 até agosto de 1949, quando os soviéticos também conseguiram testar sua primeira bomba nuclear. Na década de 1950, outros tipos de bombas nucleares sugiram, como as termonucleares, e foram testadas pelos soviéticos. Em agosto de 1953, no polígono de Semipalatinsk, no território atual do Cazaquistão, a União Soviética testou sua primeira bomba de hidrogênio, ARDS-1. Embora os EUA também tivessem desenvolvido bombas de hidrogênio, na lógica dissuasória da guerra o empate estratégico nuclear não era satisfatório para os atores evolvidos. À medida que bombas nucleares poderiam ser lançadas do espaço, o equilíbrio de poder estabelecido no início da Guerra Fria havia sido comprometido.

Além dos testes com bombas nucleares e de hidrogênio, neste período, por meio do projeto Vanguarda, houve duas tentativas frustradas dos EUA em lançar satélites no espaço. Em 1957, para surpresa dos EUA, os soviéticos, precursores no domínio do espaço sideral, lançaram o Sputnik, primeiro satélite artificial a orbitar a Terra. A partir deste enorme passo, os estadunidenses se sentiram intimidados, na medida que, se os soviéticos poderiam lançar satélites ao espaço, nada os impediria de lançar também armamentos nucleares que cruzassem o espaço. Em esforço conjunto do Jet Propulsion Laboratory (JPL) e da Army Ballistic Missile Agency (ABMA), neste mesmo ano, os EUA conseguiram modificar o veículo de lançamento Júpiter-C, mais conhecido como Juno I, e construir o satélite Explorer I. Enquanto os EUA trabalhavam na construção de seu primeiro satélite, a União Soviética enviava ao espaço seu segundo satélite, o 
Sputnik 2. Em fevereiro de 1958, o Explorer I foi lançado ao espaço e a descoberta do Cinturão de Van Allen reposicionou os EUA no centro da corrida espacial. Em 1960, o governo estadunidense transferiu os programas espaciais civis para a Nasa, os programas espaciais militares para as três Forças Armadas e concentrou alguns projetos estratégicos militares de Pesquisa e Desenvolvimento $(\mathrm{P} \& \mathrm{D})$, que envolviam energia, processamento de dados e tecnologias táticas, na Darpa. Foi nesta agência que a Arpanet, antecessora da Internet, foi desenvolvida para garantir a segurança das comunicações em caso de ataque inimigo com bombas nucleares.

Em 1958, os EUA deram início a Operação Argus, que consistiu no lançamento de três foguetes de combustível sólido X-17 armados com ogivas nucleares de baixa intensidade, disparados a partir do navio USS Norton Sound e explodiram a uma altitude de cerca de $480 \mathrm{~km}$. Esta era primeira vez que bombas nucleares foram disparadas em altitudes elevadas. O principal objetivo desta operação secreta era, a exemplo dos cinturões de Van Allen, recém-descobertos pelos satélites Explorer, criar cinturões de radiação artificiais ao redor da Terra, e assim, estudar as implicações que estas radiações gerariam nas telecomunicações, radares, mísseis balísticos e suas ogivas nucleares. Em maio de 1958, a Armour Research Foundation, financiada pelo Exército dos Estados Unidos, com sede no Instituto de Tecnologia de Illinois, iniciou estudos classificados como ultrassecretos sobre a possibilidade e as consequências de testes de bombas nucleares na Lua. Estudos semelhantes já haviam sido realizados pela RAND Corporation, em 1956, por Edward Teller, criador da bomba de hidrogênio, em 1957. A proposta de Teller era estudar explosão de bombas nucleares nas proximidades da superfície lunar.

O projeto A119, o qual consistia em um estudo investigativo também ultrassecreto de voos lunares, liderado por Leonard Reiffel, diretor da NASA, reuniu uma equipe de dez pessoas em Chicago para estudar a visibilidade de explosões de bombas nucleares na superfície da lua, possíveis benefícios para a ciência e consequências para a superfície lunar. Um dos integrantes desta equipe era Carl Sagan, responsável pela projeção matemática da expansão da nuvem de poeira no arredor da Lua, dado imprescindível para calcular a visibilidade de tal nuvem a partir da Terra. O sigilo do projeto A119 foi comprometido por Sagan tentar obter um financiamento estudantil em 1959.

Os estudos acadêmicos e legais sobre explosões de bombas nucleares eram debatidos tanto nos EUA quanto na União Soviética desde o lançamento do Sputnik I, em 1957, e submetidos a diversos organismos internacionais, em especial à $\mathrm{ONU}$. Eugène Pepin, então diretor do Instituto de Legislação Aérea e Espacial da Universidade de McGill, no Canadá, em au- 
la inaugural, em 20 de abril de 1959, neste Instituto, ao questionar as razões de acadêmicos e advogados afirmarem que eram prematuros estudos sobre a legalidade e os riscos das detonações nucleares no espaço afirmou que

esse modo de pensar prevalece entre os advogados seguidores da tradicional "common law". Para eles, a lei é processo que se desenvolve caso a caso; "decisões específicas para questões específicas originadas de casos específicos", parece-lhes ser o melhor caminho aberto à lei (Pepin 1959, 190).

Neste sentido, os estudiosos de temas legais argumentavam que o conhecimento científico sobre a natureza física do espaço diante de interferências militares humanas era demasiadamente incipiente para proferir aplicação de princípios legais, prever consequências no presente e que estas detonações podem ou não serem nocivas para a segurança humana. De acordo com Pepin,

foi dito também que aqueles que favorecem a conclusão imediata de uma convenção sobre problemas espaciais pertencem a nações que ainda não competem pela conquista do espaço. Isso não é verdade. Tanto nos Estados Unidos como na USSR a conveniência de uma convenção ainda que cobrindo apenas certos pontos específicos foi defendida, e agora pode-se afirmar que o reconhecimento da necessidade de desenvolver ou pelo menos de estudar as regras legais que devem governar as atividades humanas no espaço e suas consequências na terra está ganhando terreno $(1959,190)$.

Em 1962, durante a Operação K, a União Soviética detonou uma bomba de 30okt nas cercanias de Dzhezkazgan, cidade no Cazaquistão, a uma altitude de $290 \mathrm{~km}$. O pulso eletromagnético destruiu mil km de cabos de energia de potência que se encontravam enterrados entre as cidades de Aqmola e Almaty e fundiu $570 \mathrm{~km}$ de linha telefônica. Neste mesmo ano, o astronauta estadunidense John Glenn realizou o primeiro voo ao redor da Terra.

Também em 1962, outra operação estadunidense de testes nucleares em elevadas altitudes chamada Starfish-Prime ocorreu. A altitude em que a bomba foi detonada foi de $400 \mathrm{~km}$ sobre as Ilhas Johnston, no Oceano Pacífico. Segundo o físico Ângelo Antônio Leithold,

foram observados sinais eletromagnéticos muito fortes durante a explosão atômica, ocorreram perturbações do campo magnético da Terra significantes, as correntes de terra induzidas na superfície se fizeram sentir em todo Planeta. O pulso eletromagnético ficou reverberando por um bom tempo. As induções eletromagnéticas nas rochas ígneas da Terra reverberam também no seu núcleo (Leithold 1998, 1-2). 
Diversos testes foram realizados nestas ilhas pelos EUA, mas falharam por problemas no sistema de direção e na ignição das bombas. O local foi contaminado por plutônio. Conforme acrescenta Leithold,

a aproximadamente 1.500 quilômetros de distância do epicentro da explosão, sobre o Havaí, o pulso eletromagnético (EMP) criado, danificou trezentos postes de iluminação pública. A emissora local de televisão e várias emissoras de rádio foram literalmente queimadas. Alarmes contra assaltos em diversas localidades foram destruídos ou dispararam. Os fios de alta tensão das distribuidoras de energia elétrica das cidades próximas à região da explosão se fundiram. Também diversos transformadores de alta potência foram danificados. Os sistemas de controle de tráfego (sinaleiros, etc.) pararam de funcionar ou foram destruídos $(1998,2)$.

Os sinais eletromagnéticos da Starfish-Prime permaneceram por anos arredor do planeta e pelo espaço sideral. A partir das experiências catastróficas destas operações, em 1963, EUA e a União Soviética assinaram o Tratado de Interdição Parcial de Testes, em Moscou, proibindo testes nucleares na atmosfera, debaixo d'água e no espaço. Contudo, outros países como a Inglaterra, a França e a China também conseguiram, a partir da década de 1960, a desenvolver bombas nucleares e de hidrogênio, realizando diversos testes com detonações e buscando também conquistar o domínio do espaço sideral. Apesar da assinatura do Tratado, a corrida tecnológica pela supremacia no espaço sideral continuou.

Em 1969, a NASA liderou um programa espacial que conduziu três tripulantes da nave espacial Apollo XI, os astronautas Edwin Aldrin Jr., Neil Armstrong e Michael Collins, à Lua, garantindo assim a supremacia dos EUA no espaço sideral. Feito que, até hoje, nenhum outro Estado conseguiu repeti.

\section{ESTUDOS DE CASOS}

\section{Supremacia aérea e energia dirigida: emprego da aviação a laser}

O avanço da ciência e a descoberta de novos meios de controle de fontes energéticas têm possibilitado número crescente de notícias sobre aparatos que, de alguma forma, manejam a tecnologia de amplificação da luz por emissão estimulada de radiação, o laser.

As armas laser fazem parte de uma definição mais ampla, das denominadas Armas de Energia Dirigida (AED). Elas manipulam diferentes formas de energia eletromagnética a depender dos objetivos visados: diodo laser de baixa potência, laser químico de alta potência, ondas milimétricas ou mi- 
cro-ondas. A priori, estas armas seriam usadas como meios de defesa contra mísseis balísticos, incluindo dispositivos na órbita espacial da Terra.

As armas a laser têm sido desenvolvidas progressivamente desde a década de 1960, em paralelo a uma série de descobertas científicas e de conquistas tecnológicas. Elas diferem das armas tradicionais, classificadas como armas cinéticas, tais como armas portáteis e explosivos que destroem seus alvos por meio da transferência de energia cinética, pelos fenômenos de alta pressão, perfuração, estilhaçamento ou incêndio. O resultado produzido por armas cinéticas é o dano ou fogo, que podem ser fatais para o alvo. Enquanto as armas cinéticas se baseiam em propelentes com energia química ou ogivas explosivas projetadas sobre algum alvo, as AED compartilham o conceito de projeção de uma grande quantidade de energia armazenada pela própria arma, sobre um alvo, produzindo neste dano estrutural ou incendiário.

A maior parte da literatura contemporânea agrega em conjunto uma gama de AED diferentes, incluindo o laser de alta potência (High Energy Laser), micro-ondas de alta potência (High Power Microwave), armas de feixe de partículas e de plasma induzido por laser (Laser Induced Plasma Channel). As duas primeiras classes destas armas podem ser descritas como AED genuínas, enquanto que as armas de partículas seriam melhor classificadas como armas de projéteis, as quais se utilizam de partículas atômicas ou subatômicas aceleradas a velocidades relativísticas. Por fim, as armas de plasma seriam um híbrido, que utilizam o laser para ionizar a trajetória de partículas, através da qual uma descarga elétrica alcança um alvo, causando efeitos catastróficos.

Destas quatro categorias, os lasers de alta potência são as que teriam maior potencial no futuro próximo. Embora as micro-ondas de alta potência tenham um potencial equivalente, não foram suficientemente estimuladas pelos institutos de pesquisa. As armas de plasma teriam uma maior utilidade como armas não-letais, enquanto que as de partículas ainda estão distantes da realidade, tanto pelo tamanho quanto pelo custo envolvidos.

Especula-se que na próxima década haverá uma ampla introdução de armas laser de alta potência, com capacidade operacional, no arsenal dos EUA. Tais armas possuirão capacidades ímpares para atacar alvos na velocidade da luz, reduzindo consideravelmente a eficiência de muitos dispositivos cinéticos, especialmente mísseis balísticos (La Porta e Feller 2017). Entretanto, o entusiasmo acerca da iminência do uso corriqueiro e em larga escala das AED não é compartilhado por todos os estudiosos, que enfatizam a existência de barreiras significativas para o sucesso das armas laser no curto prazo, notadamente a dificuldade para transpor soluções tecnológicas laboratoriais para validação no ambiente operacional, com base em 
conceitos operacionais, lógicos e materiais compatíveis com a segurança que se espera de um sistema de armas. Não se minimiza ainda a questão de enfrentar-se a definição de uma possível política de emprego destas armas segundo os conceitos ainda vigentes no direito e nos costumes internacionais (Gutheinz 2006).

Além dos EUA, é reconhecida a existência em estágio avançado de programas similares na Rússia, na China e na Índia (Feickert 2018), embora os EUA tenham sido o primeiro país a desenvolver experimentos com potencial militar realista. No início dos anos 1970, já era claro para o Departamento de Defesa estadunidense que seria viável um sistema de arma laser aerotransportado usando a tecnologia disponível, uma ideia propagada ativamente nos anos 1960 pelo físico Edward Teller, um dos criadores da bomba de hidrogênio. Em 1973, a força aérea derrubou um veículo aéreo não-tripulado no Estado do Novo México, usando um laser a gás dinâmico (sigla em inglês, GDL); em 1976 o exército destruiu alguns veículos não tripulados com laser de alta energia (High Energy Laser), no Alabama; e em 1978 a marinha abateu um míssil TOW (Tubelaunched, Optically-tracked, Wire-guided, em inglês) do exército, com laser químico, na Califórnia. Existem, dessa forma, programas de armas de energia dirigida nas três forças armadas estadunidenses, prioritariamente para uso aeroespacial.

No domínio aeroespacial, ainda em 1976 a Força Aérea estadunidense (USAF) lançou o programa do laboratório laser aerotransportado (Airborne Laser Lab - ALL), instalando um dispositivo GDL sobre avião de transporte modificado, capaz de rastrear e destruir alvos aéreos. Apesar de experimental, já tinha como objetivo a destruição de mísseis balísticos, sob o lema da paz através da luz). A mesma tecnologia foi o esteio teórico do programa de defesa antimísseis Guerra nas Estrelas, da administração Reagan (1981-1988), a ser empregado com apoio de complexo sistema de espelhos adaptativos e sensores preposicionados na órbita terrestre.

Utilizando as lições aprendidas durante o programa ALL, a USAF lançou em 1996 outra iniciativa similar, denominada simplesmente laser aerotransportado (Airborne Laser - ABL), desta vez instalando emissores de laser químicos infravermelhos de alta energia (Chemical Oxygen Iodine Laser - COIL HEL) em aeronaves Boeing 747.

A concepção de defesa antimíssil prevaleceu, projetando-se o ABL para ser empregado em tempos de crise patrulhando o espaço aéreo vizinho ao de um país que ameaçasse disparar mísseis balísticos com ogivas nucleares e outras armas de destruição em massa, de tal forma que, se disparados, seriam abatidos ainda na fase inicial (tropopausa), assegurando-se que os destroços e ogivas caíssem no território do próprio país 
lançador. Mas logo se cogitou de uma segunda aplicação, como arma antissatélite, eficaz para destruir ou inutilizar satélites ou veículos espaciais de reconhecimento em órbita baixa. Com base na tecnologia ABL, em 2006 foi lançada a iniciativa do laser tático avançado (Advanced Tactical Laser-ATL), integrada por sistemas COIL HEL menores e mais baratos instaladas em plataformas de transporte Hercules AC-130 Spectre, para ataque ao solo em missões de apoio cerrado. $\mathrm{O}$ sistema teria sido utilizado experimentalmente com sucesso contra alvos em terra, em testes no Novo México.

Já na Rússia, ainda durante o período soviético, teve início o programa Almaz/Beriev A-60, com o primeiro protótipo de uma aeronave de transporte Ilyushin Il-76 Candid equipada com emissores de laser de alta potência em 1981, e um segundo em 1991. Não é plenamente conhecida a tecnologia dos emissores russos, porém, considerando-se as pesquisas da empresa Almaz com a tecnologia GDL (a mesma experimentada pelo programa ALL dos EUA), em sistemas de combate terrestre, analistas estimam que estes sejam a base da plataforma russa, o que seria consistente com a linha de teórica Terra-3, concebida desde o início para desenvolver defesas antimíssil balístico (Zarubin e Pol'skikh). Analistas também chamam atenção para o fato de que, tendo sido expostos pelo menos 20 anos antes na Rússia, os emissores do sistema estadunidense ABL apresentados em 2006 parecem ter adotado a mesma configuração.

Em 2016, o estabelecimento de pesquisa e desenvolvimento da empresa Almaz teria anunciado a conclusão de uma versão modernizada do programa A-60. O Ministério da Defesa da Rússia publicou nota oficial do vice-ministro da defesa Yuri Borisov, que o seu país possui armas laser baseadas em uma tecnologia já bem conhecida e confiável, não mais no estágio experimental, prontas para início operacional em plataformas aéreas entre 2020 e 2022 (Tass 2017), fato aparentemente reafirmado pelo relatório de 2018 do Diretor de Inteligência Nacional dos EUA, para o congresso estadunidense. (Coats 2018).

A China possui programas de AED baseada principalmente nas tecnologias de laser químico infravermelho (COIL) e de laser de elétrons livres (Free Electron Lasers - FEL), além de outra série de iniciativas com o uso de laser em diferentes modalidades (principalmente terrestres e de baixa intensidade), que não importam a este estudo. Os primeiros experimentos ainda na década de 1960 foram conduzidos com laser em estado sólido (Solid State Lasers - SSL), de baixa potência.

O desenvolvimento da tecnologia FEL estaria a cargo da Academia Chinesa de Engenharia e Física, e resultou na ativação do dispositivo SG1, em 1993. Por outro lado, a tecnologia COIL teria sido designada ao 
Instituto Dalian de Química e Física, desde a década de 1980, conduzindo ao primeiro teste de um dispositivo com alcance de $140 \mathrm{~km}$ e 1993 .

A China parece concentrar esforços em plataformas de ataque em grandes bases terrestres, com emissores apontados para alvos em órbita terrestre baixa, isto é, com objetivo primordial antissatélite. Artigo científico de 2013 teria revelado a realização de um experimento exitoso em 2005, danificando um satélite em órbita a aproximadamente $600 \mathrm{~km}$, através de um laser de 50-100KW de potência posicionado na província de Xinjiang (Gao, Zhou and Wang 2013). Isto se coaduna com a estratégia de basear outros sistemas de longo alcance em terra, a exemplo de mísseis hipersônicos antinavio.

Esta estratégia, por outro lado, poderia ser indício da dificuldade chinesa para miniaturizar as estruturas de acondicionamento de elementos químicos e de geração de grande quantidade de energia, necessárias ao emprego de sistemas de energia dirigida. Isto é, poderiam se encontrar um passo aquém dos programas ALL/ABL estadunidense e A-60 russo. Apesar disso, há relatos de que em evento militar de outubro de 2009 teria sido revelado um teste bem-sucedido de aeronave quadrimotor utilizando dispositivo laser para atacar um satélite, com base em plataforma previamente anunciada de aparelho produzido pela Xian Aircraft Corporation. Especula-se que a China possa ter um programa de laser aerotransportado com tecnologia COIL, mas que, diferentemente dos sistemas russos e estadunidenses, voltados para emprego antimíssil, a plataforma chinesa também seria projetada primordialmente para uso antissatélite (Fisher Jr 2017).

A Índia ingressa no cenário de desenvolvimento de AED há relativamente pouco tempo, ao que parece em resposta à ameaça chinesa ao seu próprio programa espacial, que caminhou paralelamente ao esforço indiano de desenvolvimento de mísseis balísticos e de seu programa nuclear. $\mathrm{O}$ programa espacial da Índia teve início na década de 1960, com apoio dos EUA, França e Alemanha, principalmente na área de satélites. O programa de veículo lançador caminhou em paralelo, com o objetivo não declarado de desenvolver o sistema de míssil balístico intercontinental Agni- $V$.

A situação geoestratégica indiana é condicionada pela ameaça perene dos países vizinhos, especialmente a China e o Paquistão, com os quais já travou guerras ainda no século XX, além de constantes atritos nas faixas de fronteiras. Assim como a Índia, tanto a China como o Paquistão possuem arsenal nuclear e mísseis balísticos. É essencial aos indianos, portanto, a manutenção de sistemas tanto ofensivos quanto defensivos no campo aeroespacial, aptos a reagir contra eventuais agressões de nações confrontantes.

É neste contexto que, a partir de 2008, a Índia teria incrementado investimentos de natureza militar no setor espacial (Sarti 2015). Para isto, 
o Organismo de Pesquisa e Desenvolvimento em Defesa (Defense Research and Development Organisation - DRDO) teria iniciado, a partir de 2014, o desenvolvimento de um sistema de armas de energia dirigida antimíssil e antissatélite. Estariam sendo exploradas a tecnologia COIL e de laser de fibra de alta potência (Highpower Fiber Laser), de uso estratégico (Bose 2014).

Em dezembro de 2017 o DRDO anunciou o teste com sucesso de uma plataforma laser de $1 \mathrm{KW}$ instalado sobre um caminhão, em Chitadruga, na presença do ministro da defesa, Arun Jaitley. Não é claro qual o princípio utilizado pelo dispositivo deste teste, mas há notícias de que o Centro de Ciência e Tecnologia Laser (Laser Science E̊ Technology Centre - LASTEC) vinha trabalhando em projeto com as mesmas características, baseado na tecnologia COIL. O LASTEC também estaria projetando um sistema baseado na tecnologia de laser a gás dinâmico (GDL), mesmo princípio utilizado pelo ALL dos EUA, e pelo A-60 russo, denominado Aditya (Gurung 2017).

Ainda não existe previsão para a instalação de sistema equivalente para teste a bordo de aeronave. Porém, já haveria estudos para uma versão aerotransportada do sistema de micro-ondas (outra classe de armas de energia dirigida) KALI (Kilo Ampere Linear Injector), em uma aeronave Ilyushin Il-76, a mesma utilizada pelo projeto A-60 russo. Considerando-se o tamanho, o tipo de sensores para aquisição de alvos e as características de um dispositivo de energia dirigida por micro-ondas, é realista imaginar que também um sistema laser possa ser empregado na mesma plataforma.

\section{Propulsão espacial a fusão nuclear}

O propósito de sistemas de propulsão em naves espaciais é alterar a velocidade delas, criando um impulso superando o alto grau de arrasto gravitacional, modificando o percurso da nave orbital. A viagem tripulada que conduziu a Apollo 11 até a Lua era propulsada por compostos químicos; no entanto, estes compostos químicos não são mais suficientes para gerar o impulso necessário para conduzir as próximas viagens tripuladas até o planeta Marte. Além de exporem a tripulação a meses de radiação espacial, a propulsão química não assegura energia e velocidade necessárias para mover espaçonaves por um longo período de tempo.

A propulsão nuclear é um sistema de propulsão que tem por base a reação nuclear como fonte primária de potência, seja por fissão ou por fusão, que pode ser empregada em diversos tipos de belonave, desde submarinos e navios aeródromo até quebra-gelos e foguetes espaciais. Existem diversos modelos de propulsão nuclear, tais como propulsor de fragmento de fissão, propulsão de pulso nuclear catalisado de antimatéria, reator propulsor de núcleo gasoso, propulsão Bussard, propulsão de pulso nuclear, 
propulsor de radioisótopo, propulsor elétrico-nuclear, propulsor de fusão nuclear, propulsor de fragmento de fissão, propulsor fotônico-nuclear, propulsor térmico nuclear, navegação de fissão, propulsão nuclear de água salgada, etc.

Em 1946, o matemático estadunidense Stanisław Ulam elaborou um memorando com os cálculos preliminares para desenvolver uma nave espacial gerada pela energia de explosões de diversas bombas atômicas no laboratório de Los Alamos, o qual foi denominado projeto Orion. Ulam foi um dos cientistas que participou do projeto Manhattan, produzindo as primeiras bombas nucleares, na Segunda Guerra Mundial. O objetivo deste projeto era combinar o pulso nuclear com a elevada velocidade de escape da nave espacial Orion com meganewtons de empuxo. A partir daí, surgiram outros sistemas experimentais de propulsão nuclear em naves espaciais, como o reator experimental soviético de fusão nuclear denominado Tokamak. Este reator foi inventado na década de 1950 pelos físicos nucleares soviéticos Igor Tamm e Andrei Sakharov, ambos inspirados pelo físico Oleg Lavrentiev sobre o domínio da fusão termonuclear. De acordo com C. M. Braams e P. E. Stott no livro Nuclear Fusion: Half a Century of Magnetic Confinement Fusion Research,

Oleg Lavrentiev, que já mostrara sua paixão em 1949, fizera posteriormente cursos de física e encontrara uma posição no Instituto de Técnicas Físicas de Kharkov. Seu esquema de confinamento eletrostático tomava a forma de um plasma, separado de um campo magnético de cúspides por uma fina camada limite. Um potencial eletrostático positivo foi imposto na cúspide do anel e nos dois pontos das cúspides por meio de eletrodos externos. Para evitar a seleção de Debye desses eletrodos, os elétrons tiveram que ser impedidos de se acumular nas regiões de potencial positivo. Embora Lavrentiev tenha alcançado alguns resultados positivos, o trabalho nas instalações do Atol no Instituto Kurchatov revelou um transporte anômalo na camada limite. Enquanto a idéia de confinamento eletrostático ressurgiu de tempos em tempos, há um grande experimento nessa linha (Braams and Sttot 2002, 84).

O Tokamak, o qual gera um campo magnético na forma de toroide (anel), no qual é guardado o plasma ${ }^{3}$ e onde as reações de fusão nuclear ocorrem, se tornou a maior referência para todos os próximos reatores de fusão nuclear que existem. O lançamento da primeira bomba de hidrogênio, criada a partir da fusão nuclear, a partir da década de 1950, rendeu ao físico germano-estadunidense Hans Bethe (1906-2005) o Prêmio Nobel de Física de 1967. Como mencionado por Braams e Stott, o reator experimental de fusão nuclear eletrostática apresentou resultados pro- 
missores e logo foram comercializados numa campanha de incentivo ao uso pacífico da energia nuclear. No final da década de 1980, o químico britânico Martin Fleischmann (1927-2012) e o químico estadunidense Stanley Pons (1943-) publicaram um artigo intitulado e traduzido para o português Fusão nuclear de dêuteron eletroquimicamente induzida sobre um novo tipo de reator de fusão nuclear sustentada que ficou mais conhecida como fusão a frio. Este artigo teve enorme repercussão internacional, mas a comunidade científica em geral não foi convencida sobre os resultados positivos do reator. Apenas alguns cientistas apoiaram o trabalho de Fleischmann e Pons.

No início da década de 1990, a partir dos resultados positivos de um projeto de fusão nuclear desenvolvido em cooperação entre EUA e União Soviética, esta modalidade de reator voltou à opinião pública. O resultado desta cooperação, em 1992, foi a decisão de construir um reator termonuclear experimental internacional com base no modelo tokamak por meio da fusão deutério-trício em uma parceria estratégica que reuniu EUA, Rússia, Comunidade Europeia, Japão, China e Coréia do Sul. O nome deste experimento é International Thermonuclear Experimental Reactor (ITER).

A empresa estadunidense Lockheed Martin's Advanced Development Programs (ADP) anunciou em 2013 a pretensão de construir um reator de fusão nuclear denominado Compact Fusion Reactor (CFR), menor do que o reator do ITER. Uma das aplicabilidades deste reator é a propulsão nuclear por meio de um reator compacto para viagem espacial até o planeta Marte em menor tempo do que as viagens espaciais são realizadas atualmente. Em agosto de 2017, o engenheiro Thomas McGuire, gerente do projeto do reator de fusão compacta da ADP apresentou o plano de desenvolvimento e status sobre o CFR, no qual cita o caminho para a energia limpa e ilimitada: ciclos de design rápido construídos para o sistema de auto aquecimento e usinas elétricas de 100 MWe em 2020. Os resultados até o momento são promissores - alvo frio e plasma denso e estável, adequado para aquecimento com feixe neutro. Os próximos experimentos de aquecimento irão investigar transição para beta alta, modo de bainha de confinamento, subsistemas de modelagem, diagnóstico e longo prazo são boas oportunidades de colaboração e paralelismo desenvolvimento para acelerar o progresso (Mcguire 2017, 7). Em matéria publicada no jornal The Drive, em março deste ano, foi anunciado que, em fevereiro deste mesmo ano, a Lockheed Martin obteve uma patente para parte do sistema de confinamento do reator de fusão. De acordo com informações sobre o McGuire, o objetivo deste projeto é ter um reator de fusão experimental em cinco anos, e dentro de dez anos produzir e comercializar reatores desta modalidade (The Drive, 2018). 
Em artigo publicado por Atul Pant, pesquisador Fellow do Institute for Defence Studies and Analyses (IDSA), em Nova Déli, na Índia, intitulado Compact Fusion: Are the Energy Equations About to Change?, o autor diz o seguinte:

o reator de fusão compacto utilizará isótopos de hidrogênio como deutério e trítio como combustível (como em outros tokomaks) e uma fonte de nêutrons para a reação. $\mathrm{O}$ reator pesquisado tem apenas dois metros de comprimento e um metro de diâmetro (chamado de reatores compactos lineares) contra tokamaks que são relativamente grandes em tamanho. $\mathrm{O}$ conceito de contenção de plasma sendo trabalhado é novo e muito diferente dos tokamaks, com resultados supostamente melhores. A energia produzida no reator estaria na forma de calor, que seria aproveitado através de uma turbina como em um reator de fissão. Mas, ao contrário do caso dos reatores de fissão, os subprodutos do reator de fusão seriam o hélio e os nêutrons não radioativos. Os nêutrons seriam absorvidos por uma manta de lítio nas paredes do reator, que produziria mais trítio - encontrado apenas em raras quantidades na Terra (Pant 2018).

Em 2010, a Revista Time fez a seguinte pergunta ao astrofísico britânico Stephen Hawking (1942-2018): "qual descoberta científica ou avanço você gostaria de ver em sua vida?”. Em resposta, Hawking afirmou que, "eu gostaria que a fusão nuclear se tornasse uma fonte de energia prática. Proporcionaria um suprimento inesgotável de energia, sem poluição ou aquecimento global". (Time 2010) Considerando a fusão nuclear como a fonte de energia das estrelas, de fato, se controlada, se constitui como uma fonte potencial de energia limpa, segura, praticamente inesgotável e de viabilidade econômica atrativa para a humanidade. A comunidade científica em geral continua dividida sobre o caráter promissor dos reatores a fusão nuclear. Os que apoiam estão confiando na reputação e nas conquistas anteriores da ADP.

Apesar do pessimismo de parte da comunidade científica, há muitas iniciativas e projetos na área de fusão nuclear em vigor. Com o apoio do cofundador da estadunidense Microsoft, Paul Allen, as também empresas estadunidenses Tri Alpha Energy e Google estão trabalhando em parceria para desenvolver novos algoritmos computacionais na área de engenharia da fusão nuclear.

Em abril deste ano, a parceria entre o Instituto de Tecnologia de Massachusetts (MIT) e a empresa estadunidense Commonwealth Fusion Systems recebeu o aporte de 50 milhões de dólares que para viabilizar um novo projeto de fusão nuclear baseado no modelo tokamak que está previsto para entrar em operação em 15 anos. Existem outros tipos de reatores 
de fusão nuclear em construção no mundo que operarão com tecnologias diferentes do modelo tokamak, como o projeto do reator alemão Wendelstein $7-X$, do tipo estelarator sem corrente e sem pulsos, o projeto de reator de fusão à frio da empresa estadunidense Brilliant Light Power, o qual operará com célula eletrolítica que usa água pura como combustível para gerar energia fundindo átomos de hidrogênio em "hidrinos", e o projeto de reator de fusão hidrogênio-boro viabilizado graças às grandes fontes de laser, capazes de atingir mais de três bilhões de graus celsius, ${ }^{5}$ desenvolvido na Universidade de Nova Gales do Sul, na Austrália e liderado por Heinrich Hora.

Todos estes projetos mencionados também têm aplicabilidades na área espacial, particularmente na propulsão de foguetes e naves espaciais. Stephen Hawking, por exemplo, defende a exploração e os múltiplos usos do espaço sideral e o emprego de tecnologias revolucionárias para viagens de longo curso e colonizações interplanetárias. Segundo Eric Hunting, diretor do The Millennial Project,

os recursos da Terra são limitados, isso é um fato. Vamos sim precisar nos expandir para outros planetas. Mas a colonização do espaço não é uma coisa que vai acontecer em um período curto de tempo. Nós não temos a tecnologia para isso. É um trabalho em conjunto que vai ultrapassar gerações, mas que precisa ser iniciado agora (Correio Braziliense 2010).

Na Universidade de Washington, nos EUA, pesquisadores financiados pela NASA também estão envolvidos na construção de componentes de uma nave espacial propulsada a fusão nuclear que substituam o utilizado atualmente. Litros de combustíveis usados em foguetes equivale a um grão do material que gera o plasma, prometendo aos astronautas realizarem viagens a Marte em 30 a 90 dias. Em 2017, anunciou-se que a NASA criou uma empresa especificamente voltada para o desenvolvimento de foguetes movidos a fusão nuclear, a Princeton Satellite Systems (PSS). O Laboratório de Física de Plasma de Princeton e a PSS estão desenvolvendo conjuntamente um revolucionário motor de fusão nuclear: o Direct Fusion Drive (DFD). Este motor também será compacto e se compromete com a queima limpa, mas promete mais empregabilidade que o reator compacto da Lockheed Martin. Além de o DFD produzir potência e empuxo de 1 a 10 MW com alta potência específica e reduzir o tempo de viagem, amplificou a variedade de missões espaciais, como missões robóticas para planetas exteriores, missões humanas para a Lua ou Marte, missões para o espaço interestelar próximo, implantação do Telescópio James Webb, Pontos de Lagrange, deflexão de asteroide, missão às luas geladas de Júpiter, módulo 
orbital e de pouso em Plutão, Alpha Centauri, telescópio de lente gravitacional $550 \mathrm{AU}$, potência terrestre modula e móvel, etc.

A NASA já anunciou seu novo plano de construção de base lunar denominado Deep Space Gateway e Elon Musk, CEO da empresa estadunidense SpaceX, detalhou durante o $68^{\circ}$ Congresso Internacional de Astronáutica, na Austrália, em setembro de 2017, o aporte financeiro e o plano de construir um foguete reutilizável denominado Big Falcon Rocket (BFR), capaz de conduzir uma nave espacial até ao espaço transportando até 100 pessoas, deixando-a em órbita enquanto o foguete retorna à Terra.

\section{CONCLUSÃO}

A exploração geopolítica aeroespacial é um tema relativamente novo no universo acadêmico e exige uma ótica mais refinada sobre os avanços científicos, tecnológicos e de inovação. É um universo ainda em processo de construção do conhecimento que exige novas teorias geopolíticas e novos pensadores interessados nos múltiplos usos dos espaços desde o aéreo ao espacial.

Warden, por exemplo enfatizou a importância do planejamento estratégico das operações antes da realização das campanhas aéreas no teatro de operações. Embora o bombardeio estratégico - atacar o teatro inimigo fora do teatro de operações - seja a espinha dorsal do poder aéreo, tese sustentada pelos teóricos do poder aéreo clássico, como Douhet e Mitchell, as novas tecnologias, em especial as com maior precisão, têm contribuído nos debates político-estratégicos a fim de, ao invés de bombardear alvos militares, industriais e civis para degradar as forças inimigas, buscar elaborar uma teoria do poder aéreo, como Boyed e Warden têm defendido, que inviabilize a capacidade estratégica e operacional dos inimigos. As armas a laser, como mencionado, se enquadram como AED e despontam no cenário do poder aéreo como uma tecnologia de quarta geração que pode preencher esta lacuna teórica. A geopolítica tem significativa contribuição na definição do emprego da aviação a laser nos teatros de operações militares aéreas, em especial, na inviabilização da capacidade estratégica e operacional dos inimigos, reorientando costumes e órgãos normativos do Direito Internacional.

Embora a fusão nuclear esteja sendo estudada desde o período pós-Guerra Fria, apenas recentemente projetos promissores de fusão nuclear controlada estão surgindo. Aqui foram apresentados alguns destes projetos promissores que envolvem entidades públicas e privadas que operam em universidades, empresas, laboratórios, centros de pesquisas e que recebem aporte financeiro de governos, parcerias público-privadas, de associações 
internacionais, empresas privadas, etc. A fusão nuclear controlada como fonte de energia limpa, segura e inesgotável tem despertado a comunidade científica para novos horizontes de oportunidades, da geração de energia à propulsão espacial.

A exemplo do físico estadunidense Robert Goddard (1882-1945) e do cosmonauta russo Konstantin Tsiolkovsky (1857-1935), entusiastas das viagens espaciais, o astrofísico estadunidense Carl Sagan (1934-1996) e Stephen Hawking, além das viagens espaciais, também defendiam e apoiavam o desenvolvimento de tecnologias revolucionárias, a exploração geopolítica do espaço sideral e a colonização interplanetária. As tecnologias de fusão nuclear expostas neste artigo têm se demonstrado cada vez mais viáveis em longo prazo no atendimento destes objetivos.

\section{REFERÊNCIAS}

Almeida, André Luiz de. 2006. A Evolução do Poder Aeroespacial Brasileiro. Dissertação, Mestrado, FFLCH/USP, São Paulo. Disponível em: http://www. teses.usp.br/teses/disponiveis/8/8136/tde-19062007-153215/publico/TESE_ ANDRE_LUIZ_ALMEIDA.pdf

Araújo Neto, José Carlos de. 2011. Fundamentos da Formulação Estratégica do Programa de Reaparelhamento Naval Brasileiro de 1906. Dossiês Militares. Revista Mestrado em História, Vassouras, V. 13, Nº 1. Disponível em: http://www.uss.br/ pages/revistas/revistaMestradoHistoria/v13n12011/pdf/005_Fundamentos_ formulcao_estrategica.pdf

Bose, Bishwajit. 2014. "Directed Energy Weapons for the Indian Armed Forces". Journal of Defense Studies, vol. 8, n. 1. Disponível em: https://idsa.in/system/ files/8_1_2014_DirectedEnergyWeaponsfortheArmedForces.pdf

Braams, C. M.; Sttot, P.E. 2002. Nuclear Fusion: Half a Century of Magnetic Confinement Fusion Research. IoP: London.

Coats, Daniel R. 2018. "Worldwide Threat Assessment of the US Intelligence Community". Office of the Director of National Intelligence. Washington. Disponível em: https://www.dni.gov/files/documents/Newsroom/Testimonies/2018-ATA--Unclassified-SSCI.pdf

Feickert, Andrew. 2018. U.S. "Army Weapons-Related Directed Energy (DE) Programs”. Congressional Research Service. Washington. Disponível em: https:// fas.org/sgp/crs/weapons/R45098.pdf 
Fisher Jr, Richard D. 2017. "Testimony before the US-China Economic and Security" Review Commission Hearing "China's Advanced Weapons". Washington. Disponível em: https://www.uscc.gov/sites/default/files/Fisher_Combined.pdf

Gao, Min-hui; Zhou, Yu-quan; Wang, Zhi-hong. 2013. "Development of Space Based Laser Weapons" Chinese Optics". Changchun Institute of Optics, Fine Mechanics and Physics. Disponível em: http://www.chineseoptics.net.cn/CN/article/downloadArticleFile.do?attachType=PDF\&id=9082 26

Gurung, Shaurya Karambir. 2017. "India gets a step closer to laser weaponry as DRDO successfully tests laser system”. The Economic Times, Mumbai.

Gutheinz, Lee. 2006. "Laser weapons: The future is now". Laser Focus World. 42. 60-61. Disponível em: https://www.researchgate.net/publication/299261680_ Laser_weapons_The_future_is_now

La Porta, James; Feller, Stephen. "Lockheed contracted to develop airborne laser capability". United Press International. Disponível em: https://www.upi.com/ Defense-News/2017/11/06/Lockheed-contracted-to-develop-airborne-lasercapability/3711509992968/?utm_source=sec\&utm_campaign=sl\&utm_medium $=1$

Leithold, Ângelo Antônio. 1998. A operação Starfish-Prime. Curitiba. Revisado em Março de 2010. Disponível em: <https://pt.scribd.com/document/29319717/ OPERACAO-STARFISH-PRIME $>$. Acesso em: 12 dez de 2018.

Lockheed Martin Now Has a Patent For Its Potentially World Changing Fusion Reactor. 2018. The Drive. Disponível em: http://www.thedrive.com/the-warzone/19652/lockheed-martin-now-has-a-patent-for-its-potentially-worldchanging-fusion-reactor.

Machry, Telmo Roberto. 2006. “O Poder Aéreo e a Estratégia da Paralisia de John Warden”. Revista da Universidade da Força Aérea. Rio de Janeiro, 18 (21). Disponível em: https://pt.scribd.com/document/83586515/O-Poder-Aereo-e-a-Estrategiada-Paralisia-John-Warden

Marí, Jose Maria Prats. "La Guerra de Mando y Control y la Teoria OODA LOOP". Dial Net. Disponível em: https://www.google.com.br/url?sa=t\&rct=j\&q $=\&$ esrc $=$ s $\&$ source $=$ web\&cd $=24 \& \mathrm{cad}=\mathrm{rja} \& u a c t=8 \& \mathrm{ved}=0 \mathrm{CCOQFjADOBRqFQo}$ TCPbR592y38gCFUgSkAoduv4AhQ\&url=http\%3A\%2F\%2Fdialnet.unirioja.es $\% 2 \mathrm{Fdescarga} \% 2$ Farticulo\%2F 4604097.pdf\&usg=AFQjCNFoSMl3A7AWtXBsw c1UZKHODT5-JA\&bvm=bv.105841590,d.Y2I 
Mcguire, Thomas. 2017. "Compact Fusion Reactor - CFR". Overview, Status And Development Plan. Disponível em: https://arpa-e.energy.gov/sites/default/ files/10_MCGUIRE.pdf

Moreira, Adriano; Cardoso, Pedro (Org). 1994. Estratégia. Lisboa: Instituto Superior de Ciências Sociais e Política.

O futuro está lá fora? 2010. Correio Braziliense. Disponível em: https://www.correiobraziliense.com.br/app/noticia/ciencia-e-saude/2010/08/24/interna_ciencia_saude,209471/o-futuro-esta-la-fora.shtml

Pannazolo Neto, Álvaro. 2013. As políticas de reaparelhamento da FAB: Associações entre Política Externa e Forças Armadas. Dissertação, Mestrado, UNB. Brasília. Disponível em: http://repositorio.unb.br/bitstream/10482/13367/1/2013_ AlvaroPanazzoloNeto.pdf

Pant, Atul. 2018. "Compact Fusion: Are the Energy Equations About to Change?” Institute for Defence Studies and Analyses. Disponível em: <https://idsa. in/idsacomments/compact-fusion-are-the-energy-equations-about-to-change_ apant_100118>.

Pepin, Eugène. 1959. Problemas legais do espaço. Razões por que os problemas legais referentes ao espaço e sua solução devem ser estudados sem demora. Revista de Direito Público e Ciência Política, V. 2, No 2. Disponível em: http://bibliotecadigital.fgv.br/ojs/index.php/rdpcp/article/view/59213/57653

Pinto, Pedro Miguel Xavier Estrada Fontes. 2003. Giulio Douhet e John Warden. Aspectos Evolutivos da Teoria do Poder Aéreo. Revista Nação \&̊ Defesa. N. ${ }^{\circ} 106$ - $2^{a}$ Série. Disponível em: https://comum.rcaap.pt/bitstream/10400.26/1372/1/ NeD106_PedroMiguelXavierEstradaFontesPinto.pdf

Russia is developing advanced hypersonic weapons - ministry. 2017. Agência Russa de Notícias. Disponível em: http://tass.com/defense/926145

Sarti, Josiane Simão. 2015. "O Programa Espacial da Índia: evolução, características e implicações". Centro de Estudos Internacionais sobre Governo. UFRGS. http://www.lume.ufrgs.br/bitstream/handle/10183/137170/Poster_42424. pdf? sequence $=2$

10 Questions for Stephen Hawking. 2010. Time. Disponível em: http://content. time.com/time/magazine/article/o,9171,2029483,00.html

Warden, John A. 1998. “The Air Campaign Planning for Combat”. National Defense University. Disponível em: http://www.au.af.mil/au/awc/awcgate/warden/wardtoc.htm 
RBED, v. 5, no 1 , jan./jun. 2018

Zarubin, V.; Pol'skikh, S. D. From the history of High Energy Lasers and Laser Based Systems in USSR. PSI. Disponível em: http://psi.ece.jhu.edu/ sasha/ IRUSS/Engl.High.Energy.Lasers.pdf 


\section{NOTAS}

1. Naquela época, bombardeiros eram aviões militares projetados para lançar bombas sobre alvos terrestres.

2. Meios bélicos capazes de sustentar os sistemas de defesa das Forças Armadas.

3. Gás quente e ionizado.

4. Conceito criado e patenteado por Randell Mills, CEO da empresa estadunidense Brilliant Light Power.

5. 200 vezes mais quente do que o núcleo do Sol. 


\section{GEOPOLÍTICA E O DOMÍNIO AEROESPACIAL: DA SUPREMACIA DA AVIAÇÃO MILITAR À EXPLORAÇÃO ESPACIAL POR FUSÃO NUCLEAR}

\section{RESUMO}

Este texto aborda teorias e conceitos da geopolítica que subsidiaram os vários usos do espaço, desde o poder aéreo ao espacial. Para além da corrida armamentista, a Guerra Fria também significou um período de grandes mudanças e inovações tecnológicas na área aeroespacial. Este artigo tem por objetivo demonstrar por meio de dois estudos de casos, energia dirigida e a aviação a laser e propulsão nuclear espacial, como estas mudanças e inovações tecnológicas ocorreram e como transformaram os estudos aeroespaciais futuros.

Palavras-chave: Geopolítica aeroespacial; Corrida tecnológica; Aviação a laser; Propulsão nuclear espacial.

\section{ABSTRACT}

This text approaches theories and concepts of geopolitics that subsidized the various uses of space, from air to space power. In addition to the arms race, the Cold War also meant a period of major changes and technological innovations in the aerospace industry. This paper aims to demonstrate through two case studies, directed energy and laser aviation and space nuclear propulsion, how these changes and technological innovations occurred and how they transformed the future aerospace studies.

Keywords: Aerospace geopolitics; Technological race; Laser aviation; Space nuclear propulsion. 